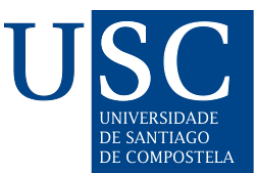

Télos. Revista Iberoamericana de Estudios Utilitaristas, 24(1-2), 2021. ISSN-e: 2255-596X

https://doi.org/10.15304/telos.24.1-2.8085

Artículos por Invitación

\title{
LA ÉTICA UTILITARISTA DE JEREMY BENTHAM: DEL SER AL DEBER SER ${ }^{1}$ \\ Jeremy Bentham's Utilitarian Ethics: From Is to Ought
}

José L. Tasset ${ }^{1}$ iD

jose.tasset@udc.es

${ }^{1}$ Universidade da Coruña, España

Recibido: 07/11/2020; Aceptado: 07/11/2020

\section{Resumen}

Jeremy Bentham es unánimemente reconocido como un filósofo político y del derecho de primera fila; también es muy reconocido como economista o teórico de la economía; desde luego, es considerado como uno de los grandes reformadores sociales del siglo XIX; incluso, recientemente, desde el último cuarto del siglo XX, ha comenzado a ser visto como uno de los grandes expertos clásicos en historia de la sexualidad y como un pensador radical en este ámbito. Pero ¿fue Bentham un gran filósofo, especialmente un gran filósofo moral?

Palabras clave: Jeremy Bentham; David Hume; utilitarismo del acto; utilitarismo de la regla; pluralismo ético; niveles de moralidad.

\begin{abstract}
Jeremy Bentham is unanimously recognized as a leading legal and political philosopher; He is also widely recognized as an economist or theorist of economics; of course, he is considered one of the great social reformers of the XIX century; even recently, since the last quarter of the 20th century, he has begun to be seen as one of the great classical experts in the history of sexuality and as a radical thinker in this field. But was Bentham a great philosopher, especially a great moral philosopher?
\end{abstract}

Keywords: Jeremy Bentham; David Hume; act utilitarianism; rule utilitarianism; ethical pluralism; levels of morality.

\section{PRESENTACIÓN. A VUELTAS CON BENTHAM}

Cuando el profesor y maestro Pedro Schwartz me llamó para invitarme a participar en este Seminario sobre la Correspondencia Ibérica de Jeremy Bentham, me estaba sometiendo a una cura de desintoxicación intelectual anti-benthamita.

Después de casi dos años luchando con los textos y manuscritos de Bentham sobre las "irregularidades sexuales", el profesor de la UCA Francisco Vázquez y yo, habíamos conseguido 
entregar una versión en cristiano relativamente comprensible a la editorial Laetoli, el libro acababa de salir publicado (Bentham, Tasset Carmona, \& Vázquez García, 2021) y yo me disponía a disfrutar del delicioso placer de editar la correspondencia de la disputa entre Hume y Rousseau, un prodigio de sutileza y belleza retórica, aunque a veces esté muy cerca del insulto personal.(Hume, en prensa, 2022)

Y en ello estaba, disfrutando de la extravagancia de Rousseau y de la indignación del pobre Hume, buscando a Sultán, el perro perdido de Rousseau por las calles de Londres, cuando Pedro Schwartz me llamó y me dio la noticia: quería que hablara de Bentham y, además, de Bentham en cuanto filósofo moral.

Durante más o menos una semana tuve pesadillas recurrentes con textos inescrutables (Francisco Vázquez y yo estuvimos una semana completa descifrando un solo párrafo de "Of sexual irregularities"), pero luego decidí que era el momento oportuno de ajustar cuentas con Jeremy Bentham en lo que es mi campo de especialización, la filosofía moral.

Así que lo que presento brevemente aquí es una suerte de vindicación, o de venganza, según se vea, en torno a Bentham y su filosofía moral.

\section{INTRODUCCIÓN}

Bentham es unánimemente reconocido como un filósofo político y del derecho de primera fila; también es muy reconocido como economista o teórico de la economía; desde luego, es considerado como uno de los grandes reformadores sociales del siglo XIX; incluso, recientemente, desde el último cuarto del siglo XX, ha comenzado a ser visto como uno de los grandes expertos clásicos en historia de la sexualidad y como un pensador radical en este ámbito. Pero ¿fue Bentham un gran filósofo, especialmente un gran filósofo moral, a secas?

En primer lugar, la ética de Bentham no es completamente original, ni siquiera muy original. Desde luego, Bentham puede, sin duda, ser considerado el auténtico proponente del modelo utilitarista de racionalidad moral, en especial en su proyección política, pero el utilitarismo clásico que propuso recogía una gran cantidad de conceptos y formulaciones de autores anteriores, Epicuro, Helvetius, Hutcheson, Beccaria, y, en especial y por encima de todos, de David Hume. Esta última deuda fue reconocida sin demasiados problemas por Bentham en diversos lugares de su obra y de su correspondencia, pero luego fue rechazada por el propio Bentham, primero, por no abrazar Hume el Principio de Utilidad como única explicación o fundamento de la moral y la política, y después por John Stuart Mill, quien consideraba a Hume un conservador y un escéptico (muy de acuerdo con la visión de Hume en el XIX). Así que quizás como filósofo a secas, y como filósofo moral, Bentham no fue tan original como sus intérpretes y devotos quizás querrían o como en un análisis rápido pudiera parecer y, principalmente, recogió las ideas de la corriente epicúrea y secular(ista) presente en el pensamiento británico de los siglos XVII y XVIII, desarrollando sus implicaciones prácticas en el ámbito político, jurídico y de la reforma de las instituciones, normas y costumbres. Que no es poco.

Intentemos argumentar y fundar este punto de vista general. 


\section{LOS LUGARES DE LA FILOSOFÍA MORAL DE BENTHAM}

La ética de Jeremy Bentham, cuyos rasgos generales constituyen el objeto primordial de este trabajo, se encuentra magistralmente presentada en su estructura en el capítulo I de la Investigación sobre los principios de la moral y la legislación y en toda la primera parte de esta obra. (Cito por la ed. de Bentham, Burns, Hart, \& Rosen, 1996)

Su desarrollo completo se encuentra en la Deontología. (Cito por la ed. de Bentham \& Goldworth, 1983)

Finalmente, la historia y explicación de sus fuentes y del proceso de su desarrollo se pueden encontrar en su "Artículo sobre el utilitarismo (versiones breve y larga)". (Cito también por la ed. de Bentham \& Goldworth, 1983) ${ }^{2}$

En todo caso, y como señala acertadamente Gerald Postema el objetivo básico de Bentham no es ético sino jurídico y político: “articular una 'ciencia de la legislación' utilitarista...-un conjunto de principios racionales en términos de los cuales puedan ser evaluadas las leyes y las propuestas de reforma social." (cfr. Postema, 2006; 2013, p. 137) En cualquier caso, los dos supuestos principales sobre las que se asienta este edificio se formulan inicialmente en la parte ética de la teoría de Bentham: (a) un principio básico normativo, el "principio de utilidad" (los seres humanos son racionales); y (b) una generalización, en principio descriptiva, pero que luego Bentham desarrollará en sus aspectos normativos, "el principio de auto-preferencia o auto-interés" (los seres humanos, además de racionales, son egoístas y autointeresados).

Así que Bentham comienza con la Ética y después continúa con la Política, el Derecho y la Reforma, que son sus auténticos intereses. La Ética es el punto de partida, pero Jeremy Bentham no se ocupa demasiado de ella, sobre todo de sus problemas teórico-normativos. Incluso le afea a Hume no haber dado el salto desde la Ética a la reforma práctica, a la modificación de las instituciones, que es lo verdaderamente importante para Bentham.

Así que la ética y sus supuestos proporcionan el fundamento para los planteamientos políticos y jurídicos posteriores, por los que Bentham es más conocido y recordado, y a los que el resto de los participantes de este Simposio seguro que dedican mucha atención. Yo me voy a conformar con centrarme en la Ética de Jeremy Bentham y en los problemas que ésta tiene, a mi juicio, para pasar - justificadamente claro está- del plano descriptivo al normativo, y del plano de la moral individual (paramétrica) a la colectiva (estratégica). Este ámbito, previo en sentido epistemológico a la política y el derecho, muestra algunas importantes limitaciones del pensamiento benthamiano.

La estructura sinóptica del argumento de Bentham que conduce de esa base ética a la conclusión reformista es la siguiente.

\section{EL ARGUMENTO CENTRAL DE LA ÉTICA DE BENTHAM. DEL PLACER INDIVIDUAL AL INTERÉS COLECTIVO}

Jeremy Bentham, a partir de su formación materialista y empirista en la filosofía de Hume y Helvetius, considerará que toda acción individual y/o política puede ser examinada en términos de placer y dolor. No hay más. Éste sería un análisis empírico de lo que de hecho hacen las personas, que es máximamente relevante para la segunda parte del proyecto de Bentham, el análisis filosófico 
de lo que deberían hacer esas mismas personas desde un punto de vista no sólo individual sino también colectivo y finalmente político.

Cómo los seres humanos están conformados para buscar el placer y huir del dolor, deberían comportarse de un modo que maximizara su utilidad, entendida ésta como la producción de la mayor felicidad para el mayor número, lo que, volviendo de nuevo al principio, es para Bentham maximizar el placer y minimizar el dolor.

De este esquema general hedonista y materialista, surge un proyecto filosófico perentorio para Bentham, que es el de diseñar y construir un buen sistema de gobierno y de leyes, que no será otro que aquél que, partiendo de cómo las personas son en realidad (buscadores de placer) contribuya a poner los medios para que lleguen a ser cómo deberían ser (maximizadores de su utilidad).

Hasta aquí el resumen muy muy sintético, y seguramente injusto, de cómo Bentham partiendo de la ética llega a la reforma política y legal de las instituciones. Esa es la parte más conocida y brillante. La parte estrictamente ética del argumento de Bentham, sin embargo, no ha sido analizada con mucho detalle hasta ahora.

Nosotros vamos a centrarnos precisamente en esa parte ética.

Para ello vamos a desarrollar con algo más de precisión sus tesis principales (algo ocultas en su conexión directa con la política y el derecho) y los posibles problemas que implican, para acabar, en la conclusión, proponiendo una alternativa para una de las principales dificultades que presenta la ética de Bentham y en realidad cualquier ética utilitarista clásica.

\section{LA DEFINICIÓN DE LOS CONCEPTOS BÁSICOS DE LA ÉTICA EN BENTHAM}

Como no podemos hacer una presentación completa de la teoría ética formulada por Jeremy Bentham, nos restringiremos, en aras de una mayor brevedad, a resumir y extractar la brillante presentación benthamiana de los problemas y conceptos de la Ética contenida en el capítulo I de la IPML, lo que cómo verán dará para mucho.

En los marginalia, Bentham comienza apuntando: "La humanidad está gobernada por el dolor y el placer." (Bentham et al., 1996, p. 11)

Desde ahí, Bentham comienza estableciendo lo que podríamos considerar su Hedonismo antropológico, más que psicológico:

"La Naturaleza ha colocado a la humanidad bajo el gobierno de dos regidores soberanos, dolor y placer. Sólo por ellos fijamos lo que debemos hacer, así como determinamos lo que haremos. Por un lado, la norma de lo correcto y lo incorrecto; por el otro, la cadena de causas y efectos, están atados a su trono." (Bentham et al., 1996, p. 11)

Con vistas a la posterior valoración de Bentham como filósofo moral, es importante darse cuenta ya, lo que es evidentemente criticable, de que tan sólo en un párrafo, y además el primero, Bentham mezcla y parece confundir el hedonismo que podemos llamar antropológico (filogenético, de la especie y derivado de estructuras instintivas; bonum faciendum, malum vitandum), el psicológico u ontogenético, del individuo, y el ético o normativo. Esto no sería un problema insoluble si posteriormente explicara cómo se transita de uno a otro. Pero, a mi juicio, no lo hace.

La ventaja del principio de utilidad frente a otros principios, es que reconoce su punto de partida en el sometimiento al dolor y al placer, lo que hace que el resto de teorías ${ }^{3}$ sean erróneas desde su base: "El principio de utilidad reconoce esta sujeción y la asume como fundamento de ese sistema 
cuyo objeto es alcanzar la construcción de la felicidad por medio de la razón y de la ley." (Bentham et al., 1996, p. 11)

En nota al pie Bentham señala que el Principio de Utilidad es un mero resumen sintético del Principio de la mayor felicidad del mayor número.

El mero término "utilidad" reconoce que no hace referencia tan directa como la expresión "mayor felicidad" a las ideas de placer y dolor, ni señala específicamente al número o cantidad de intereses afectados, como elemento determinante para la formación del criterio de lo correcto e incorrecto.

Sentado esto, Bentham procede a definir el Principle of Utility:

\begin{abstract}
“...ese principio que aprueba o desaprueba cada acción...de acuerdo con la tendencia que parezca tener a aumentar o disminuir la felicidad de la parte cuyo interés está en juego; o lo que es la misma cosa, en otras palabras, a promover u oponerse a esa felicidad. Digo de cada acción, cualquiera que sea, y por consiguiente no sólo de cada acción de un individuo, sino de cada medida de gobierno." (Bentham et al., 1996, pp. 11-12; cursivas mías)
\end{abstract}

Si interpretamos los actos como acciones particulares o como tipos o clases de acción obtenemos la clásica diferenciación entre Utilitarismo del acto y Utilitarismo de la regla: "La idea principal ha sido aplicar el test de la utilidad, no a los efectos de un acto en sí mismo, sino a su tendencia, a la regla bajo la cual ese acto cae." (Farrell, 1983, p. 33)

Siendo así, cuando contemplamos una acción desde el punto de vista del utilitarismo del acto, "juzgamos de la bondad de un acto en atención a que de él se derivan directamente determinadas ventajas o beneficios." (Farrell, 1983, p. 33) Por el contrario, el utilitarismo de la regla corresponde a un segundo nivel de consideración de los actos, "en el que juzgamos no ya la bondad que se derive directa o inmediatamente de un acto, sino sus consecuencias indirectas y su valor contextual." (Farrell, 1983, p. 33)

Sin entrar en muchos detalles de esta polémica interna al Utilitarismo, diremos que el consecuencialismo contemporáneo ha abandonado de modo preferente como mínimo dos rasgos del utilitarismo clásico definido por Bentham: el hedonismo y la utilidad del acto. Mi opinión es que este abandono a veces ha generado más problemas de los que resuelve, sobre todo en el caso del hedonismo. Prosigamos.

Junto a los problemas derivados directamente de la concentración del Principio de Utilidad en los actos, Bentham se desliza en su definición de este principio fundamental sin mayor dificultad, ni explicación, de la moral individual, que él llama "privada" (no siendo lo mismo, en un principio) a la moral "pública", o mejor colectiva, cuando ni los criterios ni las virtudes que soportan estos dos ámbitos tienen que ser necesariamente los mismos, como supo ver muy bien Hume con su distinción entre virtudes naturales y virtudes artificiales. ${ }^{4}$

Y por "utilidad" entiende Bentham lo siguiente:

"Por utilidad se entiende aquella propiedad en cualquier objeto por la que tiende a producir beneficio, ventaja, placer, bien o felicidad (...) o a evitar la ocurrencia de un perjuicio, dolor, mal o infelicidad a la parte cuyo interés está en consideración; si esa parte es la comunidad en general, entonces de la felicidad de la comunidad; si de un individuo en particular, entonces de la felicidad de ese individuo." (Bentham et al., 1996, p. 12)

Debe observarse otra vez aquí el tránsito "ingenuo" del individuo a la comunidad (mero agregativismo), ${ }^{5}$ así como el objetivismo también ingenuo que fija la producción del beneficio en ausencia del contexto. Contra esto, por ejemplo, Hume se dio cuenta de que la utilidad podía ir vinculada al tamaño del grupo ${ }^{6}$ y al propio contexto social. 
Benham, ahora sí sensatamente, define lo que entiende por "interés de la comunidad" y por la propia noción de "comunidad":

"La comunidad es un cuerpo ficticio, compuesto por las personas individuales que son consideradas como constituyéndola en tanto que sus miembros. ¿El interés de la comunidad, por tanto, es qué? -la suma de los intereses de los distintos miembros que la componen." (Bentham et al., 1996, p. 12)

Y continúa estableciendo el fundamento profundamente individualista, atomista, del utilitarismo:

\footnotetext{
"Resulta vano hablar del interés de la comunidad sin comprender cuál es el interés del individuo. Se dice de una cosa que favorece el interés del individuo, o que va a favor de su interés, cuando tiende a añadirse a la suma total de sus placeres; o lo que viene a ser lo mismo, disminuye la suma total de sus dolores." (Bentham et al., 1996, p. 12)
}

Aquí Bentham está suponiendo, pero tampoco lo explica con detalle el principio de uniformidad de placeres y dolores y de comparabilidad de estos (Rationale of Reward, Book 3, Chapter 1: "Prejudice apart, the game of push-pin is of equal value with the arts and sciences of music and poetry"), base de los elementos hedonista y bienestarista dentro del Utilitarismo Clásico, que sin embargo, John Stuart Mill cuestionará y que el consecuencialismo contemporáneo, como he dicho, también ha tendido a evitar.

Por su parte, y por tanto, una acción que está de acuerdo o se produce de conformidad con el Principio de Utilidad, o con la Utilidad, es definida del modo siguiente: "[dicha acción se produce, y está justificada moral y políticamente, se entiende]...cuando la tendencia que tiene a aumentar la felicidad de la comunidad es mayor que cualquiera que tenga a disminuirla." (Bentham et al., 1996, pp. 12-13)

Esto una vez más se aplica tanto a acciones individuales como colectivas, o como Bentham las llama, "de gobierno". (Bentham et al., 1996, pp. 7-8)

Un partidario de la Utilidad o del Principio de Utilidad es alguien para quien:

\footnotetext{
"la aprobación o desaprobación que concede a cualquier acción, o a cualquier medida, está determinada por la tendencia que conciba que tiene al aumento o disminución de la felicidad de la comunidad, y proporcionada a ésta; o, en otras palabras, a su conformidad o falta de conformidad con las leyes o dictados de la utilidad." (Bentham et al., 1996, p. 13; cursivas mías)
}

Obsérvese que Bentham usa "determinada", esto es, no sólo va unida sino "exclusivamente unida a", lo que excluye planteamientos centrados en la utilidad pero pluralistas, como una vez más el de Hume. ${ }^{7}$

En todo caso, aquí debe señalarse como algo positivo que Bentham, a pesar de ser consciente de que cualquier definición, en la medida en que aclara y expone los significados, explícitos e implícitos, está expuesta a crítica y disputa, considera que es su obligación (de cualquier filósofo moral) esclarecer casi nietzscheanamente, la denominada "fraseología moral". En este sentido, e incluso aunque podamos estar en contra del significado que da a algunos términos, su trabajo es impagable.

A continuación, lo que es crucial para la Ética, que recordemos es el campo acotado en el que estamos intentado valorar al menos globalmente la aportación de Bentham, éste procede a definir no lo que es una acción conforme a la utilidad, lo cual, a pesar de su complejidad, no deja de ser una cuestión de hecho, sino lo que es una acción "debida”, "moralmente exigible”, o lo que es lo mismo, "un deber moral", lo que entraría ya de lleno en el ámbito del "deber ser". Por su importancia cito este texto de forma completa: 


\begin{abstract}
"10. De una acción que está de acuerdo con el principio de utilidad, puede decirse siempre que es una acción que debe ser hecha, o al menos que no es una que no deba ser hecha. También puede decirse que es correcto que fuese hecha; al menos, que no es incorrecto que no fuese hecha; que es una acción correcta; al menos, que no es una acción incorrecta. Cuando son así interpretadas las palabras debe, y correcto e incorrecto, y otras de este estilo, tienen un significado; cuando ocurre otra cosa, no tienen ninguno." (Bentham et al., 1996, p. 13)
\end{abstract}

Esta conclusión, junto a una demostración de la tendencia benthamiana a complicar lo que en sí ha sido definido de modo brillante y simple, es una vez más una demostración de la influencia de la filosofía de Hume en Bentham, y no sólo en filosofía moral y política sino epistemológicamente, ya que aplica el esquema humeano de distinción entre impresiones e ideas, y la idea humeana del criterio empirista de significado (referencia de las ideas a impresiones), a la Ética y sus conceptos básicos de acuerdo con el esquema que Fred Rosen (Rosen, 2003) ha identificado con la tradición epicúrea dentro del pensamiento anglosajón: o los conceptos remiten a la utilidad, o lo que es lo mismo, a la felicidad interpretada en términos de dolor y placer, o no lo hacen. En el primer caso, tienen significado; en el segundo, no tienen significado alguno, son, por extensión, "nonsenses upon stilts". Y no hay más.

Así pues, Bentham procede a hacer con el lenguaje moral, y después con el legal, algo parecido a lo que Hume hizo con el lenguaje de la metafísica. De ahí que ambos hayan sido considerados precedentes del positivismo lógico y de la filosofía analítica. Los problemas filosóficos son en muy buena parte problemas de lenguaje. En todo caso, para Hume al menos, los errores en Filosofía se asientan sobre problemas lingüísticos, pero sólo en parte. Hay problemas filosóficos sustantivos y no sólo empíricos o lógico-lingüísticos.

A partir, por tanto, de la aplicación de un criterio empirista de significado bastante radical, Bentham remite el Principio de Utilidad, y el propio Utilitarismo Clásico, a un fundamento que podríamos llamar naturalista (Hume, una vez más) o intuicionista (Sidgwick, perteneciente a la moral de sentido común y por eso mismo no susceptible de prueba), por cuanto el esquema utilidadfelicidad-placer, y su aceptabilidad básica no pueden ser demostrados, a lo que Bentham añade que dicha prueba es innecesaria e imposible, en lo que demuestra estar de acuerdo con Hume ("hay que parar en algún sitio") (Hume, 2010) y en desacuerdo con Mill, quien lo intentó, y fracasó, en su Utilitarismo.(Mill, 1984) Dice Bentham a este respecto:

“¿Ha sido contestada la rectitud de este principio? Podría parecer que lo ha sido por aquellos que no han sabido lo que estaban queriendo decir. ¿Es susceptible de alguna prueba directa? Debiera parecer que no; porque lo que se usa para probar cualquier otra cosa, no puede a su vez ser probado; una cadena de pruebas debe tener un comienzo en algún sitio. Proporcionar esa prueba es tan imposible como innecesario." (Bentham et al., 1996, p. 13; I.11)

Este elemento naturalista procedente una vez más de Hume y de la tradición epicúrea se refleja en un texto en el que Bentham, lejos de pretender ofrecer una prueba del principio de utilidad, apela sin más a su evidencia empírica: "Por la constitución natural de la condición humana, los hombres, en la mayoría de las ocasiones de su vida, en general, abrazan este principio sin pensar en él." (Bentham et al., 1996, p. 13; I.12)

En todo caso, y eso le preocupa, lo hacen sin consistencia ni coherencia, por lo que es necesaria su explicitación y fundamentación, lo cual sería, para Bentham, la tarrea principal de la ética. Esto es, los seres humanos en general (la neuroética (Greene, 2014) y antes la teoría del desarrollo moral de Kohlberg (Jose L. Tasset, 1994) parecen haber probado empíricamente esto), funcionan según un modelo de racionalidad utilitarista, aunque no tanto del acto (Bentham) como de la regla (Hume y Mill), pero la filosofía moral, al explicitar y dar coherencia a este principio, le daría un 
estatuto normativo, por lo que ya no sólo seríamos utilitaristas de facto, sino que también quedaría establecido normativamente que debemos serlo.

Incluso la experiencia nos muestra que, cuando se combate este principio, se lo hace en el fondo "con razones extraídas, sin ser consciente de ello, de este principio mismo". (Bentham et al., 1996, p. 13; I.13) Es ilustrativo el caso de John Rawls, quien en su crítica del Principio de Utilidad, formula unos principios de Justicia que parecen asentarse, sobre todo en las excepciones (principio de la diferencia, por ejemplo), en argumentos bienestaristas colectivos de índole utilitarista. Debemos recordar que, analógicamente, lo mismo ocurre, según Bentham, con los derechos naturales y por eso es mejor fundar los derechos humanos directamente en el Principio de Utilidad, por muchas salvedades y limitaciones prudenciales que puedan establecerse en esta tarea.

\section{EL RESTO DE LA TEORÍA ÉTICA DE BENTHAM}

Bentham obviamente sigue exponiendo su compleja y muy detallada categorización de los conceptos fundamentales de la Moral en el resto de la primera parte de la IPML, así como en la Deontología y en el artículo sobre el Utilitarismo. ${ }^{8}$

Todos esos desarrollos merecerían un análisis detallado que aquí no pretendo acometer. Así que me voy a centrar en dos asuntos muy concretos.

Como explica Bentham, el paso de lo descriptivo a lo normativo, del es al debe, la clave de la ética, se resume en la cuestión de cómo pasamos de los móviles psicológicos individuales a los patrones normativos de acción colectiva. Esto es cómo mínimo cuestionable, ya que la cuestión de la fundamentación de la moral parece implicar algunos matices más allá del simple tránsito de lo individual a lo colectivo, aunque para el individualismo radical de Bentham el problema se resuma en ese paso.

Más allá de este primer problema, y después de resumir brevemente las principales críticas contemporáneas formuladas contra el modelo de racionalidad moral expuesto por Bentham (bienestarista, individualista, maximizador, agregativista y consecuencialista), añadiré por mi parte, para acabar, una crítica "post-humeana" que creo relevante y que incide en el hecho, precisamente, de que Bentham unifica y a veces confunde las formas de la racionalidad y de la moralidad individual y colectiva, al no atender a una evidente variable contextual que existe dentro de la moralidad.

Con esto, que creo que no es poco, habremos expuesto y valorado los elementos generales de la Ética utilitarista de Jeremy Bentham, una teoría que transita siempre, no sin problemas, entre el es y el debe.

\section{UNA CONCLUSIÓN CRÍTICA SOBRE LA ÉTICA DE JEREMY BENTHAM}

Si como Henry Sidgwick (Sidgwick, 1907) señaló los métodos o procedimientos de justificación de la Ética pueden ser organizados en tres grandes grupos: egoísmo o hedonismo egoísta, utilitarismo o hedonismo universalista e intuicionismo o moral del sentido común, y sentado que la moral del sentido común es contradictoria e inoperante en casos conflictivos o difíciles, ocurre que las razones egoístas serán sólidas en el ámbito individual y las utilitaristas en el colectivo, pero será imposible lograr, como pretende Bentham, una teoría omnicomprensiva que aúne ambos 
grupos de razones o formule un único modelo de racionalidad moral y política, de donde se deduce que existe una insuperable dualidad de la razón práctica, que estaría escindida entre lo individual y lo colectivo, entre la racionalidad egoísta y la universalista, en suma, entre la moralidad y la racionalidad.

Se han formulado otras muchas objeciones relevantes intra y extrasistemáticas (desde dentro del utilitarismo y desde fuera de él), contra el utilitarismo en general y específicamente contra la ética de Bentham: las que inciden en el carácter auto-contradictorio del utilitarismo del acto benthamiano, que siempre acaba disolviéndose en reglas, normas o patrones de acción; aquellas que inciden en el excesivo individualismo de su utilitarismo; en su agregatividad simple; en su paradójica falta de atención a las variables individuales; en su enfoque también simple de la maximización; en fin, incluso en su imposible psicología de partida, demasiado reductiva.

Ninguna de estas objeciones me parece insuperable y, es más, todas han sido contestadas de un modo u otro.

Otra cosa es lo que sucede con la objeción, o mejor con el problema, que Henry Sidgwick identificó brillantemente, según el cual la racionalidad utilitarista aspira a una teoría unitaria y omnicomprensiva que explique cómo se transita de lo individual a lo colectivo, o también de lo que es a lo que debe ser. Bentham realmente no explica este tránsito, sino que en cierto sentido lo da por sentado y se entrega a la tarea de la reforma social, política, jurídica, económica, sin haber resuelto adecuadamente en qué forma de racionalidad moral se puede asentar la irrenunciable tarea normativa de la ética y de las otras disciplinas normativas. ${ }^{9}$

En realidad, y aunque estuvo cerca de ver la solución cuando en su Deontología analiza lo que denomina "La lista de virtudes de Hume", no llegó a contemplar la posibilidad de que de que en la propia filosofía moral y política de David Hume pudiese estar el germen de una hipótesis que permitiera superar la escisión o dualidad de la razón de la que habla Henry Sidgwick y que caracterizaría al utilitarismo especialmente en la versión benthamiana.

De un modo necesariamente muy breve, y para acabar, presentaré la estructura general de una hipótesis, que denomino posthumeana, de explicación de la evolución de la racionalidad moral (cfr. un desarrollo más amplio en José L. Tasset, 2018). Si ésta tiene algún viso de verosimilitud, ello significaría que el propósito benthamiano de alcanzar un único principio moral (el de utilidad) y una única racionalidad moral (la utilitarista del acto) estaría muerto y errado desde un principio. Vayamos con ello.

\section{MORAL POR NIVELES}

David Hume en el THN sostenía la existencia de una evolución moral desde un ámbito natural (movido por pasiones naturales y aprobado por medio de virtudes naturales) hasta un ámbito artificial (movido por pasiones indirectas y derivadas, aprobado por virtudes artificiales), lo que tiene una importante consecuencia de tipo normativo.

La M2 o moralidad convencional o artificial, centrada en la Justicia, se basará de un modo no sólo central, sino exclusivo, en la Utilidad.

No así la M1 o moralidad natural, basada en consideraciones naturalistas (no solo en el sentido de naturales, sino de inmediatas, directas, necesitadas de poco o ningún cálculo), que pueden derivar su aprobación de la Utilidad, o no. En este ámbito es en el que tiene sentido afirmar, como hace 
Hume para escándalo de Bentham, que la Utilidad es "one foundation of morality" pero no "the sole foundation of morality". 10

Y es que habrá acciones morales en el ámbito de socialización natural (sociedades familiares o plurifamiliares) o S1, relacionadas con el carácter, demandantes de aprobación y generadoras de pautas virtuosas de comportamiento, por tanto, dignas de alabanza y de imitación, que no se basan en una Utilidad directa para el individuo: por ejemplo, el altruismo no recíproco (de modo inmediato, al menos) de un padre para con sus hijos o para con sus mayores.

Así que mi tesis básica será, siguiendo a Hume y a la vez yendo mucho más allá de lo dicho por él, que el tipo de moral tiene que estar adaptado en cada momento a la forma de interacción social, basada así o no en la reciprocidad y en la generalización de los comportamientos virtuosos individuales, dando lugar a la siguiente combinatoria posible (siendo $M$ el tipo de moral y $S$ el tipo de sociedad):

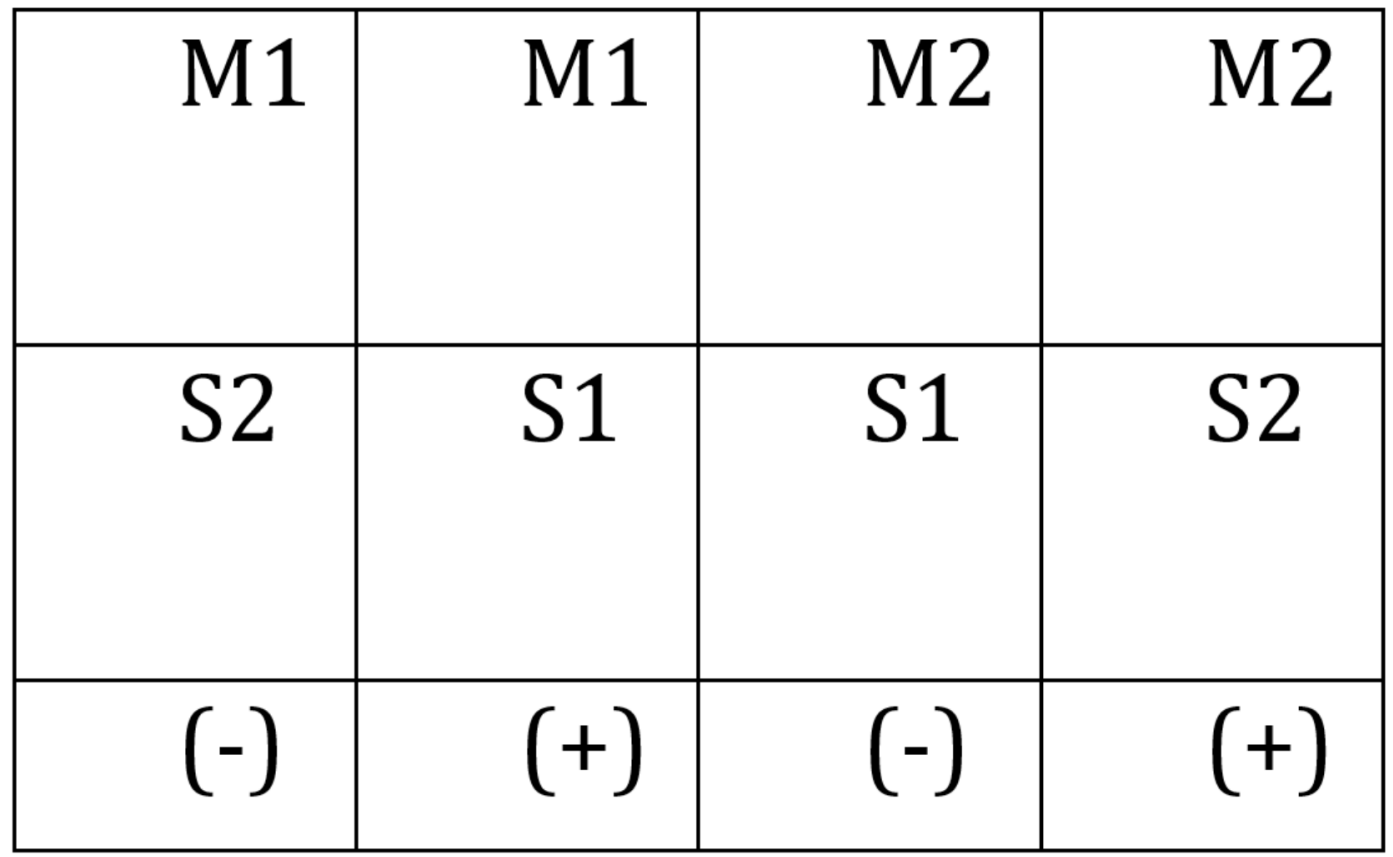

En la primera situación, intentamos funcionar con una moral natural, directa, en un entorno social complejo y fracasamos; en la segunda funcionamos con motivos y moral naturales en un entorno de socialización próximo y directo y acertamos; en la tercera, funcionamos con una moral artificial y compleja basada en la utilidad en un entorno social próximo y directo y fallamos (nuestros familiares huyen ante el intento de aplicarles una moral de tit for tat); finalmente, en el último estadio aplicamos una moral compleja de raíz utilitarista (de la regla, a mi modo de ver, y contra Bentham) en un entorno de una sociabilidad distante y compleja y tenemos éxito, porque evitamos sobre todo la paradoja del sensible knave, el ladrón inteligente que está siempre buscando a un idiota moral -o a muchos- con quien regatear (bargaining game) y a quien engañar si logra que éste -u otros muchos- siga practicando una moral solidaria y altruista directa -puede ser recíproca pero esta reciprocidad no es un requisito sine qua non-, que excluye el tit for tat, en un entorno en el que la clave es que todos practiquen una moral de una radical reciprocidad no sólo binaria sino generalizada. 


\section{CONCLUSIONES: LA MULTIDIMENSIONALIDAD MORAL Y EL UTILITARISMO CLÁSICO DE JEREMY BENTHAM}

Esta hipótesis sobre la evolución de la racionalidad moral tiene importantes consecuencias normativas,

En primer lugar, abre la puerta a una comprensión compleja de la moral por niveles.

En segundo lugar, permite llegar a comprender que estos niveles se diferencien por los siguientes factores:

a. en ellos operan distintos tipos de pasiones o disposiciones emocionales;

b. en consonancia con esto, también operan dos tipos diferentes de racionalidad, y

c. estos tipos diferentes de racionalidad se correlacionan con distintos tipos de utilidad.

Y, en tercer lugar, proporciona la intuición básica para desarrollar la idea de que cuando se opera un ajuste adecuado entre estos factores no habrá contradicción entre moralidad y racionalidad; cuando, al contrario, se produce un desajuste surge una disonancia entre moralidad y racionalidad.

Al igual que la sociedad compleja surge de estructuras familiares o endogámicas muy elementales, la moral basada en la justicia surge también de una moral cuasi-natural basada en pasiones naturales (como el amor), aunque esas pasiones no sirvan ya en un estadio avanzado y complejo de la evolución moral e institucional.

En todo caso, la tesis básica de Hume acerca de la articulación entre pasiones naturales y artificiales, de la que partimos y que Bentham no tuvo suficientemente en cuenta en el App. C a su Deontology (cfr. un análisis de la lectura benthamiana de la ética de Hume en José L. Tasset, 2017; y posteriormente en José L. Tasset, 2019), sienta las bases de un muy acertado enfoque de solución al posible conflicto entre moralidad y racionalidad, o lo que es más exacto, entre distintos tipos de moralidad, definidas por el uso de distintos tipos de racionalidad. Las pasiones artificiales se asientan sobre pasiones naturales. En el ámbito de una moralidad muy básica bastan las pasiones naturales. En el ámbito de una moralidad más compleja, se necesitan pasiones artificiales, que, no obstante, están asentadas sobre el motivo natural del interés, aunque puedan servirlo de una manera mucho más remota y distante y necesiten no quedarnos anclados en el cálculo sobre acciones puntuales sino del desarrollo de pautas o reglas. Nuestra moralidad y nuestra racionalidad pueden y deben cambiar a medida que nuestra interacción social se va volviendo más compleja y nuestros motivos naturales de acción se van volviendo más remotos. No obstante, estos motivos son la fuente primigenia de la moral y si acaban siendo contrariados de forma constante y sistemática, como plantea el problema del Sensible Knave, (cfr. J. L. Tasset, 2011) tendremos que revisar la adecuación entre nuestra moralidad, nuestra racionalidad y el contexto social en el que éstas se incardinan y realizar los cambios en ellas que permitan reajustar su relación con el contexto social. Este reajuste, a mi modo de ver, se consigue por medio de un enfoque utilitarista de la regla, aunque el utilitarismo no pueda ni deba ser la única explicación o justificación de todo el universo de la Moral.

Permanece, sin embargo, abierta la pregunta de si sería plausible una teoría que ampliara este papel de la utilidad a todo el ámbito de la Moral. David Hume, en mi opinión, pensó que esto no era ni posible ni deseable, ni siquiera necesario. Mi visión de la moralidad está de acuerdo con esta limitación. Bentham y el Utilitarismo Clásico aspiraban, sin embargo, como señala John Rawls, a hacer del utilitarismo una doctrina omni-comprensiva. Mi opinión, a partir del desarrollo post- 
humeano que he explicado brevemente, es que sería mejor que el Utilitarismo abandonara ese propósito omni-explicativo, dado el carácter complejo del fenómeno moral y la evidente existencia dentro de él de niveles explicativos distintos. Esto hará sin duda que se reduzca el alcance de la Teoría, pero aumentará su plausibilidad. Y esto no es un objetivo desdeñable. Que la moral es un fenómeno complejo y no debe ser reducido a una sola dimensión fue uno de los grandes logros de la filosofía moral y política de David Hume, lo que es lo mismo que decir, de la historia de la ética. Y Bentham lo pasó por alto en su proyecto, demasiado directo, de pasar del placer y el dolor, a la felicidad, a la utilidad, y de ahí a la reforma social urgente. Ese era un proyecto político seguramente perentorio, pero anclado en fundamentos filosófico-morales en un cierto sentido demasiado débiles.

Pero, esto nos lleva a la pregunta inicial: ¿era Bentham un genuino filósofo moral?

Dejo la pregunta en el aire, aunque creo haber articulado un esbozo de respuesta.

\section{Referencias}

Bentham, J., Tasset Carmona, J. L., \& Vázquez García, F. (2021). Sobre el homoerotismo : tres ensayos inéditos. Pamplona: Laetoli.

Bentham, J., Burns, J. H., Hart, H. L. A., \& Rosen, F. (1996). An Introduction to the principles of morals and legislation. Oxford: Clarendon Press. DOI: http://dx.doi.org/10.1093/oseo/instance.00077240

Bentham, J., \& Goldworth, A. (1983). Deontology; together with A table of the springs of action; and the Article on Utilitarianism. Oxford/New York: Clarendon Press; Oxford University Press. DOI: http://dx.doi.org /10.1093/oseo/instance.00077236

Farrell, M. D. (1983). Utilitarismo: ética y política. Buenos Aires: Abeledo-Perrot.

Greene, J. D. (2014). Beyond Point-and-Shoot Morality: Why Cognitive (Neuro)Science Matters for Ethics. 124 Ethics(4), 695-726. DOI: https://doi.org/10.1086/675875

Hume, D. (en prensa, 2022). UN RELATO CONCISO Y VERAZ DE LA DISPUTA ENTRE EL Sr. Hume y el Sr. ROUSSEAU, CON LAS CARTAS enviadas entre ellos durante sU CONTROVERSIA, Y TAMBIÉN CON LAS CARTAS del Hon. Sr. WALPOLE y del Sr. D'ALEMBERT relativas a este extraordinario asunto (J. L. Tasset, Trans.). Pamplona: Laetoli.

Hume, D. (1991). Investigación sobre los principios de la moral. Madrid: Espasa Calpe.

Hume, D. (2010). Tratado de la Naturaleza Humana (trad. de Vicente Viqueira, revisada y actualizada) (V. Viqueira, Trans.). En J. L. Tasset \& R. Díaz Seijas (Eds.), David Hume: Obra filosófica. Madrid: Gredos.

Hume, D., \& Beauchamp, T. L. (1998). An enquiry concerning the principles of morals. Oxford, New York: Oxford University Press. DOI: https://doi.org/10.1093/actrade/9780199266333.book.1

Lara, F. (2017). Oxytocin, Empathy and Human Enhancement. THEORIA. An International Journal for Theory, History and Foundations of Science, 32(3), 367-384. DOI: https://doi.org/10.1387/theoria.17890

Mill, J. S. (1984). El utilitarismo : Un sistema de la lógica (E. Guisán, Trans.). Madrid: Alianza.

Postema, G. J. (2006). Bentham's Utilitarianism. In The Blackwell Guide to Mill's Utilitarianism, West, Henry R (ed) (pp. 26-44). DOI: https://doi.org/10.1002/9780470776483.ch2

Postema, G. J. (2013). Bentham, Jeremy (1748-1832). In J. E. Crimmins (Ed.), Bloomsbury encyclopedia of utilitarianism (pp. 137-141). N.Y.: Bloomsbury. DOI: http://dx.doi.org/10.5040/9781350021679

Rawls, J. (1995). Teoría de la justicia (2a. ed.). México [etc]: Fondo de Cultura Económica.

Rawls, J. (1999). A Theory of Justice: Revised Edition. 
Rosen, F. (2003). Classical utilitarianism from Hume to Mill. London; New York: Routledge. DOI: https://do i.org/10.4324/9780203987353

Schwartz, P. (1996). Importan los hechos para los juicios morales? Una defensa contra la navaja de Hume basada en la nocion de coste de oportunidad. Telos: Revista Iberoamerica de Estudios Utilitaristas, 5(2), 87-113.

Sen, A. (2011). The Boundaries of Justice (David Hume and our world). The New Republic, 29 (December). Sidgwick, H. (1907). The Methods of Ethics (7th ed.). New York: MacMillan.

Tasset, J. L. (1994). Utilitarismo y Teoria del Desarrollo Moral (I): Analisis critico de las teorias cognitivas del desarrollo moral y de sus fundamentos Kantianos. Telos: Revista Iberoamerica de Estudios Utilitaristas, 3(1), 49-83.

Tasset, J.-L. (1997). ¿Era la ‘navaja de Hume’ propia o prestada? Los hechos y la Ética (Una argumentación humeana sobre la posibilidad y conveniencia de pasar del 'Es' al 'Debes' para una fundamentación teleológica de la Moral. Telos: Revista Iberoamerica de Estudios Utilitaristas, 6(2), 101-113.

Tasset, J. L. (2011). De ladrones y reglas (Una visión del problema del “Sensible Knave” desde un utilitarismo de la regla atemperado). Daimon, Revista Internacional de Filosofia, 52 (enero-abril), 117-140.

Tasset, J. L. (2017). Virtudes y utilidad en David Hume y Jeremy Bentham. Agora: Papeles de Filosofia, 36(1), 119-147. DOI: https://doi.org/10.15304/ag.36.1.3101

Tasset, J. L. (2018). Instituciones, evolución y delincuencia racional: hacia una perspectiva posthumeana. Araucaria: Revista Iberoamericana de Filosofía, Política, Humanidades y Relaciones Internacionales, 20(40), 349-369. DOI: https://doi.org/10.12795/araucaria.2018.i40.16

Tasset, J. L. (2019). Bentham on 'Hume's Virtues'. In G. Varouxakis \& M. Philp (Eds.), Happiness and Utility. Essays Presented to Frederick Rosen (pp. 81-97). London: UCL Press. DOI: https://doi.org/10.2307/ j.ctvf3w1s5.9

Notas

1 Este texto recoge con algunas pequeñas modificaciones la ponencia presentada en el "Seminario sobre la Correspondencia Ibérica de Jeremías Bentham", organizado por Pedro Schwartz y Fernando Becker, que se celebró en el Centro de Estudios "Economía de Madrid" de la Universidad Rey Juan Carlos de Madrid entre los días 27 y 28 de octubre de 2021. El trabajo se ha realizado en el marco del proyecto de investigación "(GEN)ESIS Y (RED)EFINICION DE LA MATRIZ CONCEPTUAL DEL (P)ARADIGMA(U)TILITARISTA DE (R)ACIONALIDAD.”(GENRED-PUR), Ministerio de Ciencia, Innovación y Universidades, referencia: RTI2018-093498-B-I00.

2 Todavía inédito en español; actualmente preparo una edición bilingüe para Télos (2022).

3 Sidgwick en Methods of Ethics y en su ensayo "Utilitarianism", de un modo más preciso, denominará al Utilitarismo, o método ético que parte del Principio de Utilidad, Hedonismo universalista, frente al simple Hedonismo egoísta o al mero intuicionismo.

4 V. la conclusión crítica de este trabajo.

5 Cfr. La Crítica de John Rawls a este hipotético agregativismo, en el marco de una exposición y evaluación general del utilitarismo clásico, llevada a cabo en (Rawls, 1995, p. 34 y ss. de la $2^{\mathrm{a}}$ ed. esp.; 1999, p. 19 y ss.)

6 V. la muy interesante exposición de los problemas implicados por un altruismo irrestricto desde el punto de vista de la teoría del moral enhancement llevada a cabo en (Lara, 2017).

$7 \quad$ He analizado por extenso esta discrepancia, fundamental, entre Hume y Bentham principalmente en (José L. Tasset, 2017).

8 Bentham es un clasificador nato, como se puede observar en ese brillante capítulo introductorio de la IPML ya mencionado. Tiene una especial capacidad para lograr segmentar las cuestiones en innumerables categorías y subcategorías, revelando aspectos ocultos de los problemas que sólo tras su categorización se ven o aprecian. También es un brillante definidor de conceptos y categorías. 
A mi modo de ver, sin embargo, pierde mucha de su brillantez cuando comienza a desarrollar sus definiciones y categorizaciones en un todo articulado, perdiendo en intensidad al irse poco a poco extendiendo demasiado en análisis, muchas veces nimios, de cuestiones que se olvidan y alejan del problema principal en cuestión.

Esto se observa en ese capítulo 1 de la IPML. Dicho capítulo es un ejemplo genial de capacidad para identificar y precisar algunos de los conceptos clave de la Ética de un modo hasta entonces seguramente nunca visto, y nada más. No hay un posterior desarrollo de sus principios generales o de sus problemas, sino una fragmentación infinita de los conceptos y categorías hasta un extremo en absoluto necesario.

9 Pedro Schwartz me objetó amablemente en una brillante intervención oral en el Seminario mencionado que, como su maestro Amartya Sen señalaba en sus clases, la objeción del paso ilegitimo del Is al Ought seguía vigente en los aparentes términos en los que la planteaba Hume y, por tanto, no parecía que la estructura de una hipótesis como la mía fuera a solucionarla, por lo que había que seguir pensando en cómo hacerlo. Un punto de vista similar a éste ya lo había expresado en (Schwartz, 1996). Mi visión muy crítica de la interpretación tradicional y aporética del Is-Ought Passage del Tratado de Hume ya la expuse hace años en (J.-L. Tasset, 1997); allí explicaba cómo Hume no se planteaba este problema en los mismos términos que la Filosofía analítica contemporánea, cómo jamás vuelve a aparecer en su obra, como tal, después del Tratado, lo que explica entre otras cosas por qué Bentham, quien analiza con detalle el pensamiento ético de Hume, ni siquiera se refiere a este problema. Mucho más recientemente he conseguido articular un desarrollo más constructivo de mi propuesta en torno a este tema, enmarcándolo en la explicación de cómo se genera una propuesta normativa de tipo institucional, que sin ser fiel a la letra de Hume, creo que hace justicia al espíritu de su propuesta global de lograr una explicación compleja de un fenómeno tan plural como la moralidad.(Cfr. J. L. Tasset, 2018) En honor a la verdad habría que señalar que el propio Sen ha defendido con posterioridad una interpretación mucho más constructiva de la filosofía moral y política de Hume, por ejemplo en la impresionante conferencia inaugural del Congreso Internacional de la Hume Society con ocasión del Tercer Centenario del Nacimiento de Hume.(Sen, 2011)

10 Cfr. A este respecto el texto fundamental de Hume en (Hume, 1991, p. 99; Hume \& Beauchamp, 1998: 5.44): "Parece que es una cuestión de hecho que en todos los asuntos la circunstancia de la utilidad es una fuente de alabanza y aprobación; que continuamente se apela a ella en todas las decisiones morales sobre el mérito y demerito de las acciones; que es la única fuente de esa alta consideración que se presta a la justicia, a la fidelidad, al honor, a la lealtad y a la castidad; que es inseparable de todas las demás virtudes sociales: de la humanidad, la generosidad, la caridad, la afabilidad, la indulgencia, la compasión y la moderación; y, en una palabra, que es el fundamento de la parte principal de la moral, la cual se refiere a la humanidad y a nuestros semejantes." 